\title{
O PERCURSO DE UMA ENTREVISTA NO JORNAL: ALGUNS PROCEDIMENTOS LINGÜÍSTICO - DISCURSIVOS NA PASSAGEM DO ORAL PARA O ESCRITO E SUAS CONSEQUÊNCIAS PARA A INTERPRETAÇÃO DA ENUNCIAÇÃO
}

\author{
Valéria Aparecida Galioti Silva Prado*
}

\begin{abstract}
Resumo: A passagem da modalidade oral para a escrita, procedimento freqüente na comunicação humana e, em especial para esta pesquisa, na imprensa escrita, produz alterações no discurso. $O$ presente trabalho procura reconhecer algumas estratégias lingüístico-discursivas utilizadas pelos jornalistas na transmissão da notícia, analisando o percurso de uma entrevista, do seu pronunciamento oral até sua publicação no jornal, para verificar em que medida tais estratégias podem servir de instrumento de manipulação de idéias, além de buscar diferenças no trato da notícia nos dois jornais analisados, levando-se em conta o comprometimento de um deles com a fonte de informação.
\end{abstract}

Palavras-chave: Análise do Discurso. Teoria da Enunciação. Polifonia. Discurso Relatado. Discurso Direto. Aspas. Verbos de Elocução.

\section{Introdução}

Uma das formas mais comuns de alteração no sentido dos enunciados e, conseqüentemente, de manipulação de informações é aquela produzida por operações bastante comuns na comunicação humana, as quais dizem respeito à passagem da língua oral para a escrita.

O presente trabalho procura conhecer as estratégias lingüístico-discursivas utilizadas pelos jornalistas na publicação de entrevistas, respondendo às seguintes questões: 1] De que maneira a imprensa escrita transforma uma entrevista oral em escrita, no que diz respeito à seleção das informações?; 2] Qual o tratamento dado ao discurso relatado (doravante DR), no que diz respeito à seleção do discurso direto (DD) e da "ilha textual em discurso indireto (DI)", além do uso dos verbos de elocução?; 3] Em que medida podem variar os efeitos de sentido obtidos por diferentes jornais, em que pese o fato de um deles ter tido acesso a uma fonte exclusiva?

\footnotetext{
* Mestre em Língua Portuguesa pela Pontifícia Universidade Católica de São Paulo - PUCSP.
} 
O corpus analisado tem como ponto de partida duas entrevistas exclusivas do exdeputado federal Roberto Jefferson, concedidas com exclusividade ao jornal Folha de S.Paulo, em 6 e 12 de junho de 2005, e publicadas também no jornal O Estado de S.Paulo, além de trechos em áudio das duas entrevistas disponibilizados pela Folha em seu site.

Partimos do exame da passagem da língua oral para a escrita, denominada por Marcuschi (2003) retextualização, seguindo um modelo das operações textuais-discursivas na passagem do texto oral para o texto escrito proposto pelo autor. Para isso, utilizamos o material gravado e transcrito, comparando-o com o material escrito publicado pelo jornal Folha de S.Paulo.

Em seguida, verificamos o emprego dos verbos de elocução quanto à sua função e à sua ação, seguindo estudiosos como Marcuschi (1991) e Urbano (2003), unânimes em afirmar que tais verbos podem agir sobre a interpretação do discurso que eles introduzem.

Por fim, analisamos o uso das aspas em duas formas de citação do discurso alheio o DD e a "ilha textual em DI" -, a partir das observações feitas por Authier-Revuz (2001) sobre o DR, a cujo estudo acrescenta outras formas de citação, além de rejeitar a visão tradicional do DD como sendo a reprodução fiel do discurso de outro, pois o que um DR relata não é uma frase ou enunciado, mas todo um ato de enunciação. Desse modo, desfazse a idéia de fidelidade do DD e abre-se a possibilidade de efeitos de sentido criados pelo enunciador para atingir determinados propósitos.

\section{A questão da retextualização}

No caso de entrevistas orais que são publicadas no jornal, na íntegra ou parcialmente, o que é bastante comum, faz-se presente a questão crucial da passagem do oral para o escrito e a conseqüente alteração do discurso, queixa freqüente de pessoas entrevistadas pelos jornais.

Esse procedimento mereceu estudo de Marcuschi (2003: 48), que identificou as operações mais comuns que os usuários realizam na passagem da fala (entrevista oral) para a escrita (entrevista impressa), uma das possibilidades de retextualização $o^{l}$. Para o autor, é inerente à passagem de uma modalidade a outra a questão da compreensão do que foi dito. Essa questão já se faz presente no primeiro nível da passagem da fala para a escrita apresentado por Marcuschi (2003: 51), que é a transcrição, uma transcodificação do sonoro para o grafemático, em que "o texto oral transcrito perde seu caráter originário e pessoal e passa por uma neutralização devida à transcodificação". Para essa operação, adotam-se uma série de convenções, que variam de um pesquisador para outro. É importante ressaltar que nenhuma transcrição é neutra, pois sofre uma primeira interpretação na passagem para a modalidade escrita.

Por outro lado, quando se faz apenas uma transcrição, como afirma Marcuschi (idem), procede-se à passagem da expressão oral, em sua substância e forma, para a expressão escrita. Quando, além da interferência na expressão, passa-se à interferência na forma e substância do conteúdo, estamos no âmbito da retextualização, a qual envolve

\footnotetext{
${ }^{1}$ Além dela, há as possibilidades de passagem da fala (conferência) para a fala (tradução simultânea), da escrita (texto escrito) para a fala (exposição oral) e da escrita (texto escrito) para a escrita (resumo escrito).
} 
questões éticas, uma vez que o transcritor pode, por exemplo, colocar em evidência a posição social ou cultural inferior do falante reproduzindo sua fala repleta de incorreções gramaticais (algumas vezes chamando mais ainda a atenção para esses erros com um "bem intencionado" sic) ou, pelo contrário, fazendo as correções necessárias, inclusive interferindo no léxico, para dar mais credibilidade ao que se diz. (idem:53).

Marcuschi prevê, para os processos de retextualização, aspectos lingüísticostextuais-discursivos-cognitivos assim distribuídos: A -idealização (eliminação, completude, regularização); B - reformulação (acréscimo, substituição, reordenação); C - adaptação (tratamento da seqüência dos turnos); D - compreensão (inferência, inversão, generalização) $^{2}$. Ao enfocar a retextualização neste artigo, pretendemos verificar em que momentos o jornal procedeu a eliminações que possam ter interferido no sentido daquilo que se quis dizer. ${ }^{3}$

\subsection{As eliminações}

Um dos procedimentos mais comuns nas retextualizações é a eliminação. Pelo fato de o planejamento da fala ocorrer ao mesmo tempo em que a sua realização, é grande a ocorrência de descontinuidades em sua formulação. ${ }^{4}$

As operações iniciais do modelo de Marcuschi (2003: 61), aquelas que dizem respeito às atividades de "idealização": eliminação, completude e regularização, visam à regularização dos fenômenos de (des)continuidade sintática, como hesitações, correções, marcadores conversacionais, repetições e truncamentos.

Além dos procedimentos de regularização lingüística, ocorre, na retextualização, a eliminação dos fenômenos que caracterizam a (des)continuidade discursiva, tais como as digressões e inserções incompreensíveis, visando à regularização discursiva.

Propomos uma análise das eliminações partindo desse critério. No plano da (des)continuidade sintática, analisaremos a eliminação de dois procedimentos: a paráfrase e a repetição, os quais, enquanto atividades de formulação textual, visam à compreensão do ouvinte e têm "o papel específico de reformular passagens do texto com vistas à formulação adequada e, em decorrência, à garantia da compreensão por parte do ouvinte." (Hilgert, 2001: 126). Nesse sentido, estamos no âmbito da interação e, sem podermos nos alongar demais no assunto que é bastante complexo, queremos assinalar que o procedimento de reformulação, segundo Barros (1998: 48) "é sempre argumentativo ou persuasivoargumentativo". No âmbito da (des)continuidade discursiva, analisaremos a digressão.

\footnotetext{
${ }^{2} \mathrm{O}$ modelo completo das operações textuais-discursivas na passagem do texto oral para o texto escrito pode ser encontrado em Marcuschi, 2003: 75.

${ }^{3}$ Para conhecer o estudo completo, ver Prado (2006).

${ }^{4}$ A descontinuidade é entendida como uma interrupção na formulação do enunciado. (cf. Hilgert, 2001:108)
} 


\subsubsection{A paráfrase}

Parafrasear é um procedimento de reformulação em que se estabelece uma relação de equivalência semântica entre dois enunciados. Essa equivalência pode variar desde um grau mínimo até um grau máximo e o deslocamento de sentido pode variar do sentido geral para o específico, havendo tendência à expansão lexical e sintática (paráfrase "expansiva"), do sentido específico para o geral, com tendência à condensação lexical e sintática (paráfrase "redutora") e, por fim, com a mesma dimensão sintática e lexical (paráfrase "paralela") (cf. Hilgert, 2001: 114). O que veremos, em nosso corpus, são paráfrases autoiniciadas, aquelas em que o interlocutor parafraseia o próprio enunciado e o jornal, por questão de economia, escolhe um dos enunciados e elimina o outro.

As entrevistas sob análise têm como interlocutores o ex-deputado federal Roberto Jefferson e a repórter do jornal Folha de S.Paulo, Renata Lo Prete. ${ }^{5}$

A paráfrase que o enunciador faz no exemplo a pode ser classificada como "expansiva", pois vai de um sentido mais geral, porque abstrato: "trair a confiança" para um mais específico, porque concreto: "jogar no meio da rua":

\begin{tabular}{|l|l|}
\hline \multicolumn{1}{|c|}{ Transcrição $^{6}$} & \multicolumn{1}{|c|}{ Retextualização $^{7}$} \\
\hline $\begin{array}{l}\text { a) sem trair a confiança do governo ... sem } \\
\text { jogar o/o governo ... no meio da rua }\end{array}$ & a) Sem jogar o governo no meio da rua \\
\hline
\end{tabular}

No exemplo b, temos uma paráfrase "paralela", em que ocorre apenas a troca de "disse", para "falei":

\begin{tabular}{|c|c|}
\hline Transcrição & Retextualização \\
\hline
\end{tabular}

\footnotetext{
${ }^{5}$ As entrevistas concedidas ao jornal Folha de S. Paulo, em 6 e 12/6/2005, foram, na verdade, a reação do exdeputado federal Roberto Jefferson diante de denúncias de corrupção nos Correios envolvendo seu nome e de seu partido em práticas que, segundo ele, eram comuns entre governo e outros partidos da base aliada também. Nas entrevistas, Jefferson denuncia um suposto pagamento de mesada pelo governo aos deputados dos partidos aliados, deflagrando o "escândalo do mensalão". Para um panorama completo do contexto histórico, ver Prado (2006).

${ }^{6} \mathrm{O}$ material gravado foi composto de trechos editados da primeira entrevista (concedida em 6/6/2005) e da segunda entrevista (concedida em 12/6/2005), veiculados pela Folha em seu site (www.folhasp.com.br), perfazendo em total de dezesseis minutos e nove segundos de gravação. O material oral foi transcrito segundo as normas de transcrição do Projeto NURC/SP (Preti, 2001:11-12).

${ }^{7} \mathrm{O}$ material retextualizado compreende as publicações das entrevistas no jornal Folha de S.Paulo nos dias $6 \mathrm{e}$ 12 de junho de 2005.
} 
b) Eu disse isso aos ministros ano paSSAdo Renata eu falei aos ministros ano passado nenhum deles pegou ... como é que isso foi chantagem? Foi advertência .b) Eu falei do "mensalão" aos ministros no ano passado. Isso não é chantagem, é advertência.

Sendo a paráfrase um procedimento de reformulação que tem como objetivo a compreensão do co-enunciador, é esperado que, se o jornal precisa eliminar um dos dois enunciados, que seja o primeiro, pois o segundo, supõe-se, vai mais ao encontro daquilo que o enunciador quis dizer, e é o que ocorre nos exemplos acima.

O exemplo c revela-nos um caso interessante de paráfrase: o enunciador, em primeiro lugar, reformula seu enunciado empregando uma paráfrase "expansiva", indo de "recuou", geral, para "retirou a denúncia do 'mensalão"”, mais específica. O jornal, por sua vez, ao fazer a retextualização, emprega uma outra paráfrase: "voltou atrás". O que observamos com essa troca é a força pragmática conferida ao enunciado, pois "voltar atrás" numa decisão é muito mais forte do que simplesmente "recuar" ou "retirar a denúncia do mensalão":

\begin{tabular}{|l|l|}
\hline \multicolumn{1}{|c|}{ Transcrição } & \multicolumn{1}{c|}{ Retextualização } \\
\hline $\begin{array}{l}\text { c) Depois ... recuou retirou a/a/a denúncia } \\
\text { do mensalão não é? }\end{array}$ & c) e depois voltou atrás. \\
\hline
\end{tabular}

\subsubsection{A repetição}

A repetição pode ser um recurso de produção do enunciado ou um procedimento discursivo, com o objetivo, por exemplo, de construir relações de afinidade ou de enfatizar o argumento utilizado (cf. Barros, 1998: 67). A sua eliminação, portanto, deverá ser vista com bastante cuidado.

O entrevistado, conhecido por sua personalidade forte e por seu comportamento dramático, utiliza, durante o trecho transcrito abaixo, inúmeras repetições, não só de expressões, mas de situações que enfatizam seus esforços para denunciar a existência do "mensalão". Tais repetições foram eliminadas ao serem editadas, para tornar o texto mais conciso. Ao se fazer isso, porém, interferiu-se no sentido que o enunciador quis conferir ao seu enunciado.

A eliminação do trecho em negrito, em a, não interfere na compreensão do enunciado, uma vez que a situação eliminada havia sido descrita em detalhes imediatamente antes dela. Roberto Jefferson, porém, ao repeti-la, quer endossar aquilo que já disse, como uma prova de que está falando a verdade e, desse modo, eliminá-la acaba por interferir nessa sua intenção: 


\begin{tabular}{|l|l|}
\hline \multicolumn{1}{|c|}{ Transcrição } & \multicolumn{1}{|c|}{ Retextualização } \\
\hline a) aí reúnem-se o bispo Rodrigues & a) Aí reúnem-se os deputados Bispo \\
Valdemar Costa Neto e o Pedro Henry que & Rodrigues (PL-RJ), Valdemar Costa Neto \\
a essa época era líder do PP para pressionar & [SP, presidente do PL] e Pedro Henry (PP- \\
o Múcio "que que é isso pô? vocês não vão & MT) para pressionar o Múcio: "Que que é \\
receber? Que conversa é essa Múcio ( ) de & isso? Vocês não vão receber? Que conversa \\
melhor do que a gente?" aí o Múcio voltou & é essa? Vão dar uma de melhores do que a \\
a mim falou "Roberto fui pressionado & gente? Aí o Múcio voltou a mim. \\
pelos três líderes ... pelo presidente do PL \\
pelo líder do PL e pelo líder do PP nessa \\
conversa do mensalão"
\end{tabular}

O caso do exemplo b é diferente, pois se eliminou uma resposta que foi dada a pessoas diferentes: a primeira vez para Martinez Correia, quando pressionado por Delúbio Soares, e a segunda para José Múcio, quando pressionado por deputados que já recebiam o "mensalão". O fato de Roberto Jefferson ter dado a mesma resposta revelaria a firmeza de sua posição e, novamente, a força ilocutória que ele queria imprimir não só a esse trecho, mas a toda a entrevista. A repetição a que ele recorre durante toda a entrevista é persuasivoargumentativa (cf. Barros, 1998: 66):

\begin{tabular}{|c|c|}
\hline Transcrição & Retextualização \\
\hline $\begin{array}{l}\text { b) eu falei "Múcio EU NÃO QUERO } \\
\text { receber ... não aceitarei isso na } \\
\text { presidência do PTB porque isso é coisa } \\
\text { "'de qui/ de câmara de vereador de } \\
\text { quinta categoria isso desmoraliza } \\
\text { O conteúdo do trecho eliminado foi dito } \\
\text { anteriormente, quando o deputado estava } \\
\text { conversando com o então presidente do } \\
\text { PTB, Martinez Correia: }\end{array}$ & b) Eu respondi: "Isso desmoraliza." \\
\hline $\begin{array}{l}\text { eu digo "sou contra ... sou contra porque } \\
\text { isso é coisa de câmara de vereador de quinta } \\
\text { categoria }\end{array}$ & $\begin{array}{l}\text { Eu digo: "Sou contra. Isso é coisa de } \\
\text { Câmara de Vereadores de quinta categoria. }\end{array}$ \\
\hline
\end{tabular}

A repetição, nos exemplos c e d, tem, novamente, função argumentativa, pois enfatiza os esforços de Jefferson para denunciar o "mensalão" e sua "bravura" ao resistir a tanta pressão, inclusive por parte de pessoas de seu partido: 


\begin{tabular}{|c|c|}
\hline Transcrição & Retextualização \\
\hline $\begin{array}{l}\text { c) falei isso ao Aldo Rebelo que era líder do } \\
\text { governo àquela época ... disse a ele ... sobre o } \\
\text { mensalão denunciei a existência do mensalão } \\
\text { e a pressão que eu no PTB recebia de alguns } \\
\text { deputados que sabendo que outros } \\
\text { deputados de outros partidos recebiam e o } \\
\text { PTB não recebia esse malfadado ... mensalão } \\
\text { O conteúdo do trecho eliminado foi dito } \\
\text { anteriormente, logo após a conversa com o } \\
\text { ministro Walfrido: } \\
\text { e passei a viver uma brutal pressão porque } \\
\text { alguns deputados de meu partido sabiam que os } \\
\text { deputados do PL do PP recebiam esse } \\
\text { mensalão todo mês } \\
\text { d)depois ... recuou retirou a/a/a denúncia do } \\
\text { mensalão não é? eu falei com ele quando ele } \\
\text { era aMIgo do governo e falei (ao presidente) } \\
\text { quando ele era Ministro das Comunicações } \\
\text {... mensalão PL PP (e queria) o PTB não é? } \\
\text {... } \\
\text { O conteúdo do trecho eliminado foi dito } \\
\text { anteriormente: } \\
\text { aí fui ao ministro Miro Teixeira nas } \\
\text { Comunicações e levei junto comigo o deputado } \\
\text { João Lira e o deputado Zé Múcio falei } \\
\text { "Ciro/Miro/Miro/Miro Teixeira/Miro tá } \\
\text { havendo o MENSALÃo isso é um escândalo" } \\
\text { o Miro falou "não é possível Roberto" eu falei } \\
\text { presidente Lula não nos recebia - - "conte isso } \\
\text { ao presidente Lula isso vai explodir AMIGO } \\
\text { isso é um esCÂNdalo vai explodir" }\end{array}$ & $\begin{array}{l}\text { Aí fui ao ministro Miro Teixeira,nas } \\
\text { Comunicações. Levei comigo os deputados } \\
\text { João Lyra (PTB-AL) e José Múcio. Falei: } \\
\text { "Conte ao presidente Lula que está havendo } \\
\text { o "mensalão". Nessa época o presidente } \\
\text { não nos recebia. }\end{array}$ \\
\hline
\end{tabular}

No exemplo e, o trecho eliminado corresponde ao relato feito por Roberto Jefferson ainda na $1^{\mathrm{a}}$ entrevista: 


\begin{tabular}{|l|l|}
\hline Transcrição & \multicolumn{1}{|c|}{ Retextualização } \\
\hline e) o PTB fora éh:: convidado a participar e & e) O PTB fora convidado a participar e \\
o PTB repelira isso disse isso ao Ciro & repelira. Acho que os ministros traíram a \\
Gomes disse isso ao Miro Teixeira e & confiança do presidente. \\
NINguém contou ao presidente essa & \\
nossa conversa ... há um ano atrás eu & \\
falei isso a eles e toda crise que nós & \\
estamos vivendo de relação hoje na & \\
Câmara dos Deputados com o Poder & \\
Executivo ... não vota corpo mole isso que & \\
você está vendo é conseqüiência dessa & \\
política de mensalão ... e acho que os & \\
ministros erraram traíram a confiança do do & \\
presidente &
\end{tabular}

A conversa com Miro Teixeira está relatada no exemplo d e a conversa com Ciro Gomes foi a seguinte:

Lá para junho eu fui ao Ciro Gomes. Falei: "Ciro, vai dar uma zebra neste governo. Tem um "mensalão". Hoje eu sei que são R \$ 3 mi, R \$ 1,5 mi de mensal para o PL e para o PP. Isso vai explodir". O Ciro falou; "Roberto, é muito dinheiro, eu não acredito nisso. (Folha de S.Paulo, 6/6/2005, A5)

Ao repetir duas das tentativas que fez para denunciar o "mensalão", Roberto Jefferson confirma o que disse na $1^{a}$ entrevista e enfatiza novamente seus esforços. A repetição tem objetivos argumentativos.

Nas duas entrevistas, portanto, elimina-se a repetição de toda a situação já descrita pelo entrevistado e, além disso, o desabafo dele em relação ao drama que estava vivendo, pressionado pelos deputados de seu partido e pela base aliada do governo para que aceitasse participar da distribuição do "mensalão", mostrando todas as tentativas que fez para que as pessoas comunicassem ao presidente o fato. Tira-se, portanto, toda a força pragmática que o entrevistado queria conferir ao seu enunciado, ao colocar-se como alguém que não mediu esforços para denunciar o "mensalão" e, acima de tudo, lutou contra ele. 


\subsubsection{A digressão}

No plano da (des)continuidade discursiva, encontramos a digressão, que, considerada sob o enfoque interacional, funciona como estratégia que visa a determinados efeitos de sentido (cf. Andrade, 2000: 100). A digressão pode ser de três naturezas: lógico experiencial, interpessoal e retórica, de acordo com o seu propósito. No primeiro caso, o propósito é de natureza pessoal, em que o enunciador direciona o foco de seu discurso para uma experiência vivida por ele. Na digressão interpessoal, o propósito é de ordem contextual. A digressão retórica contribui para a produção lingüística e subdivide-se em didática, cuja relevância é de ordem metaconversacional ou metalingüística, e persuasiva, a qual tem a intenção de manipular uma pergunta (cf. Andrade, 2000). Eliminar trechos de uma entrevista, quer seja visando à regularização lingüística ou discursiva, pode acarretar grandes alterações no sentido do enunciado. ${ }^{8}$

No exemplo a, o entrevistado utiliza a digressão, por meio de uma experiência pessoal vivida, como forma de argumentação para mostrar as conseqüências de se aceitar o recebimento do "mensalão". Nesse caso, ao relembrar de fatos acontecidos entre ele e seu pai quando ainda era criança, pretende mostrar-se como uma pessoa sincera, que possui valores morais elevados. Além disso, o entrevistado cita, em sua digressão, uma fala de seu pai, uma pessoa muito próxima e cara a ele, com o nítido propósito de "criar um efeito de verdade" (Leite, 2005: 112) sobre aquilo que ele está contando e a sua eliminação acaba por interferir em sua argumentação:

\begin{tabular}{l|l} 
Transcrição & Retextualização \\
\hline
\end{tabular}

A questão da relevância, na digressão retórica abaixo, está no fato de se utilizar um recurso metalingüístico - o significado da palavra chantagem - para argumentar em seu favor, ou seja, provar que aquilo que está fazendo não é chantagem por meio da definição da palavra:

\footnotetext{
${ }^{8}$ O jornal Folha de S.Paulo, a respeito da "declaração textual", assim se pronuncia: "A reprodução das declarações deve ser literal. Só podem ser reproduzidas entre aspas frases que tenham sido efetivamente ouvidas pelo jornalista, ao vivo ou em gravações. (...) Na reprodução de declaração textual, seja fiel ao que foi dito, mas, se não for de relevância jornalística (grifo nosso), elimine repetições de palavras ou expressões da linguagem oral: hum, é, ah, né, tá, sabe?, entende?, viu? Para facilitar a leitura (grifo nosso), pode-se suprimir trecho ou alterar a ordem do que foi dito - desde que respeitado o conteúdo" (Manual da Redação, 2006: 39). Ao mesmo tempo em que defende a literalidade da declaração, o jornal aceita que se façam eliminações e alterações seguindo-se os duvidosos critérios de "relevância jornalística" e de facilitação da leitura, sem esclarecê-los. Desse modo, o jornalista passa a ter a liberdade de fazer as alterações que quiser, respaldado por esses critérios.
} 


\begin{tabular}{|c|c|}
\hline Transcrição & Retextualização \\
\hline $\begin{array}{l}\text { b) então não é não é chantagem ... } \\
\text { chantagem o que que é ó se você não me } \\
\text { der isso eu vou contar não não se trata } \\
\text { disso ... é uma cautela }\end{array}$ & $\begin{array}{l}\text { b) Então, não se trata de chantagem. É } \\
\text { cautela. }\end{array}$ \\
\hline
\end{tabular}

O que podemos concluir, concordando com Andrade (2000: 125), é que o jornal, ao eliminar as digressões feitas por Roberto Jefferson, interfere na sua argumentação.

\section{O uso dos verbos de elocução}

É muito comum o uso de verbos para indicar o interlocutor que está com a palavra, os chamados verbos "de elocução", que Othon M. Garcia classifica em dicendi ou declarandi e sentiendi, genitivos do gerúndio dos verbos dicere, declarare e sentire, que significam, respectivamente: "de dizer", "de declarar", "de sentir" (1988:130)

Muitos estudiosos assinalam diferenças significativas no seu emprego: de um lado, existem aqueles verbos considerados "neutros", de sentido mais geral, como dizer e falar, que, com freqüência, introduzem a fala citada; de outro, existem os verbos mais caracterizadores da fala, os quais dão ao DD um enfoque subjetivo, como confessar, revelar, dentre outros. (cf. Garcia, 1988: 133; Urbano, 2003: 141; Maingueneau, 2004: 144).

Gavazzi e Rodrigues (2003: 52) afirmam que a seleção dos verbos de elocução, "além de meramente comunicar uma informação, estaria reproduzindo a ideologia predominante no jornal, espelho da classe social a que se destina/a que serve."9

Marcuschi (1991: 89), em estudo acerca do que ele denomina verbos introdutores de opiniões, faz duas distinções básicas entre os verbos dicendi: a sua "função" e a sua "ação". No primeiro caso, há uma função essencialmente organizadora dos verbos introdutores de opiniões, que é a de "costurar" os argumentos do autor de um texto préexistente. Gavazzi e Rodrigues (2003: 53) atentam para o fato de que tais verbos marcam "a fronteira entre o discurso citante e o citado, evidenciando duas enunciações". Marcuschi sugere sete classes gerais de funções organizadoras:

\footnotetext{
${ }^{9}$ O jornal Folha de S.Paulo, a respeito do que ele denomina "verbos declarativos", recomenda: "Use apenas para introduzir ou finalizar falas dos personagens da notícia, não para qualificá-las ou para insinuar opinião a respeito delas. Evite, assim, verbos como admitir, reconhecer, lembrar, salientar, ressaltar, confessar, garantir, a não ser quando usados em sentido estrito. Nenhum deles é sinônimo de dizer. Ao empregá-los de modo inadequado, o jornalista confere caráter positivo ou negativo às declarações que reproduz, mesmo que não tenha a intenção.Use de preferência os verbos dizer, declarar, afirmar, os mais neutros, quando o objetivo for apenas indicar a autoria de uma declaração." (Manual da Redação, 2006: 104)
} 
I - Verbos indicadores de posições oficiais e afirmações positivas: "declarar", "afirmar", "comunicar", "anunciar", "informar", "confirmar", "assegurar"

II - Verbos indicadores de força do argumento:"frisar", "ressaltar", "sublinhar", "acentuar", "enfatizar", "destacar", "garantir"

III - Verbos indicadores de emocionalidade circunstancial:"desabafar", "gritar", "vociferar", "esbravejar", "apelar", "ironizar"

IV - Verbos indicadores de provisoriedade do argumento:"achar", "julgar", "acreditar", "pensar", "imaginar"

$\mathrm{V}$ - Verbos organizadores de um momento argumentativo no conjunto do discurso:

"iniciar", "prosseguir", "introduzir", “concluir", "inferir", “acrescentar", "continuar", "finalizar", "explicar"

VI - Verbos indicadores de retomadas opositivas, organizadores dos aspectos conflituosos:"comentar", "reiterar", "reafirmar", "negar", "discordar", "temer", "admitir", "apartear", "revidar", "retrucar", "responder", "indagar", "defender", "reconhecer", "reconsiderar", "reagir"

VII - Verbos interpretativos do caráter ilocutivo do discurso referido:"aconselhar", "criticar", "advertir", “enaltecer", "elogiar", "prometer", "condenar”, "censurar", "desaprovar", "incentivar", "sugerir", "exortar", "admoestar"

(Marcuschi, 1991: 89)

Tais verbos constroem um texto a partir de um outro texto relatado, assumindo funções que nem sempre fazem justiça ao que foi dito originalmente (cf. Marcuschi, 1991: 90)

Nesse ponto, entramos no que ele denomina a "ação" dos verbos, uma vez que, convenhamos, existe uma grande diferença, para além da variação lexical, entre a utilização de disse, por exemplo, e confessou. Seguindo a mesma linha de Garcia (1988) e Urbano (2003), Marcuschi (1991: 84) defende a hipótese de que esses verbos hierarquizam, discriminam, classificam os autores do discurso citado.

Seguindo Maingueneau, Gavazzi e Rodrigues propõem que os verbos de elocução podem ser descritivos e avaliativos. No primeiro caso, devem-se incluir os verbos "que situam o discurso relatado na cronologia discursiva" (Gavazzi e Rodrigues, 2003: 57), como, continuar, acrescentar, concluir etc., e aqueles "que indicam o tipo de discurso do interlocutor ou modo de realização fônica do enunciado" (idem), como perguntar, responder, descrever, murmurar etc. Quanto aos verbos avaliativos, as autoras postulam que estão "mais ligados à credibilidade e à legitimidade do redator da matéria em relação ao seu entrevistado - é ele quem traduz as intenções do seu interlocutor, segundo o seu próprio ponto de vista ou de um grupo que ele representa" (idem: 58). Analisando os verbos sob essa perspectiva, a da avaliação, estaríamos, portanto, no âmbito da ação de tais verbos, que revelariam a intenção do enunciador do discurso citante nas seguintes categorias (cf. Gavazzi e Rodrigues, 2003: 57-59):

a) Efeito de imparcialidade: aqui enquadram-se verbos como dizer, falar, declarar, opinar etc., considerados "neutros" em relação a outros modalizadores, como observa Urbano (2003: 141). 
b) Valorização negativa: verbos como jurar, imaginar, garantir, acreditar, eximirse, sonhar, tentar justificar, choramingar, desconversar etc., ao serem empregados, desvalorizam a fala do entrevistado, não lhe conferindo credibilidade.

c) Valorização positiva: nesse caso, enaltece-se a figura do entrevistado, colocandoo em posição de superioridade, na qual ele pode aconselhar, explicar, pontificar, analisar, diagnosticar, ensinar, ponderar, teorizar etc.

d) Polemização: os verbos desta categoria revelam o conflito existente entre pessoas e grupos, contribuindo para acirrar ainda mais a discussão. São eles: ironizar, devolver (no sentido de revidar uma ofensa/acusação), atacar, disparar, alfinetar, culpar, gozar, cutucar, discordar, entre outros.

e) Solidariedade: utilizados quando o entrevistado encontra-se, segundo o jornalista, em posição de injustiça social, solidarizando-se com sua causa: desabafar, queixar-se, indignar-se, lamentar, pedir, lembrar.

Desse modo, acreditamos, seguindo os estudiosos citados, que o uso dos verbos de elocução, ao agirem sobre a organização do discurso relatado, acabam por agir também sobre a sua interpretação, configurando-se em poderoso instrumento de manipulação de idéias.

Partindo das sete classes gerais de funções organizadoras apontadas por Marcuschi (1991) e, no âmbito da ação de tais verbos, seguindo a proposta de categorização de Gavazzi e Rodrigues (2003), fizemos uma análise comparativa entre trechos da retextualização da entrevista do dia 12 de junho de 2005 no jornal Folha de S.Paulo e no jornal $O$ Estado de S.Paulo.

Segundo a classificação proposta por Marcuschi, temos, no trecho (1), a ocorrência dos verbos dizer e afirmar, que são "indicadores de afirmações positivas" e criam o efeito de "imparcialidade" sugerido por Gavazzi e Rodrigues, o que mostra que a Folha não pretende se posicionar claramente em relação às declarações de seu entrevistado.:

(1) 'Em nova entrevista exclusiva, presidente do PTB afirma que 'mesada' para parlamentares aliados chegava a Brasília em malas Dinheiro do 'mensalão' vinha de estatais e empresas, diz Jefferson

Em nova entrevista exclusiva à Folha, o presidente do PTB, deputado Roberto Jefferson (RJ), afirma que o dinheiro do 'mensalão' pago pelo PT a deputados de partidos aliados no Congresso vinha de estatais e de empresas do setor privado.

'Esse dinheiro chega a Brasília, pelo que sei, em malas', diz Jeferson. (...)

$\mathrm{O}$ presidente do PTB afirma não ter provas, mas diz que, em depoimento na Câmara na próxima terça, vai contar tudo o que 'vivenciou' nesta relação de dois anos e meio com o governo do PT'. (...)

Jefferson, que se diz contrário ao recebimento do 'mensalão' entre deputados do seu partido, fechou, porém, outro acordo com o PT. (...) 'O primeiro recurso chegou em julho: R\$ 4 milhões, em dinheiro, em espécie', diz.(...)” (Jornal Folha de S.Paulo) 
Tal posicionamento se confirma também nas outras páginas da Folha, resultando, quanto à função de tais verbos, no predomínio dos "verbos indicadores de posições oficiais e afirmações positivas", que agem criando um efeito de "imparcialidade", bem apropriado a um jornal que está publicando, com exclusividade, denúncias que atingem as mais altas esferas de poder do país. O jornal procura colocar-se numa posição "neutra", evitando, inclusive, polemizar, visto que só encontramos duas ocorrências de verbos dessa categoria, e, também, valorizar positivamente a figura do entrevistado, o que poderia ser um sinal de apoio, ou negativamente, o que seria um sinal de descrédito de sua fonte exclusiva.

O próximo texto sob análise, do jornal $O$ Estado de S.Paulo, inicia com o verbo contar, curiosamente não contemplado pelo estudo de Marcuschi nem pelo estudo de Gavazzi e Rodrigues. Podemos classificá-lo como pertencente à área semântica dos verbos "indicadores de afirmações positivas", como afirmar, declarar, comunicar, porém nos arriscamos a levantar a hipótese de que sua ação difere da levantada no exemplo anterior para esses verbos; contar, aqui, encaixar-se-ia na categoria "valorização negativa" do entrevistado, remetendo ao sentido "contar uma história", desacreditando-a. Vejamos se essa hipótese se confirma.

O verbo dizer, bastante presente nos exemplos da Folha, aparece apenas 2 vezes no exemplo (2). Além dele, os outros verbos que procuram criar um efeito de "imparcialidade" são afirmar (2 vezes) e informar. A locução verbal voltou a acusar e o verbo acusar, classificados como "organizadores de aspectos conflituosos", criam um efeito de "polemização"; os verbos garantir e insistir, por sua vez, "indicadores de força do argumento", valorizam negativamente a fala do entrevistado, principalmente o verbo insistir, antecedido do verbo narrar, que nos remete à hipótese levantada no início com o verbo contar. A utilização de tais verbos - contar e narrar -, até aqui, vai-se nos afigurando como uma tentativa de desacreditar a fala do entrevistado, comparando-a a uma história, fruto de sua imaginação:

(2) "Mensalão vinha na mala, conta Jefferson. (...)

Presidente do PTB volta à carga e diz que mesada a deputados era paga em dinheiro vivo, proveniente de empresas estatais e privadas

O deputado Roberto Jefferson (PTB-RJ) voltou a acusar o esquema de mesadas a deputados, afirmando que o chamado mensalão era pago em dinheiro vivo, provinha de estatais e empresas privadas, e trazido em malas, basicamente por dois 'operadores', o líder do PP na Câmara, deputado José Janene (PR), e o publicitário Marcos Valério, dono das empresas DNA Propaganda e SMP\&B, ambas de Belo Horizonte. (...)

Na nova entrevista que concedeu ao jornal Folha de S.Paulo, Jefferson garantiu que as direções do PP e do PL recebiam diretamente os recursos para pagar o mensalão. (...)

Jefferson acusou seu colega José Janene de forma contundente. De acordo com o presidente do PTB, Janene seria um dos 'operadores' diretos do esquema do mensalão, informando que ele 'vai na fonte, pega, vem'. E disse mais: ‘Eu já vi o Zé Dirceu muito irritado com ele porque ele se apresentava como 'operador' do Zé Dirceu'.

Segundo Jefferson, as dificuldades que o governo passou a enfrentar este ano no Congresso são 'uma crise de abstinência': 'O corpo mole é porque está faltando 
aquilo que o Delúbio sempre transferiu a líderes e presidentes da base: o dinheiro para pagar o exército mercenário, a bancada de aluguel', afirmou. (...)

O deputado petebista narrou as reações do presidente, insistindo na versão de que Lula chorou quando ouviu a história do mensalão: 'Foi como se alguém dissesse (para ele) 'olha ali a tua mulher com outro homem', aquela reação de surpresa, de mágoa, as lágrimas brotaram'. (...)" (Jornal O Estado de S.Paulo)

No próximo trecho (3), aparece o verbo contar (2 vezes), para o qual continuamos a defender a hipótese de "valorização negativa"do entrevistado. Verbos que poderiam ser considerados "neutros", neste trecho, são os seguintes: dizer (2 vezes), indicador de "afirmações positivas", e acrescentar e explicar, "organizadores de um momento argumentativo no conjunto do discurso"; quanto aos dois últimos, Gavazzi e Rodrigues enquadram acrescentar no quadro de "verbos descritivos" e explicar no quadro de "verbos avaliativos", na categoria de "valorização positiva" da fala do entrevistado. Estaríamos, então, errados quanto à nossa hipótese de valorização negativa do entrevistado? Não nos deixemos enganar pelas aparências, pois, logo em seguida, tal valorização é invertida, pois o mesmo verbo é repetido, seguido da expressão "como se estivesse compondo um roteiro de novela". Confirma-se aqui, portanto, nossa hipótese: a fala do entrevistado é desacreditada pelo jornal. Atacar, acusar (2 vezes), reiterar e rebater, "organizadores dos aspectos conflituosos", agem na categoria de "polemização". Esquivar-se, também com a mesma função, age, porém, na categoria de "valorização negativa", pois o assunto do qual o entrevistado trata, naquele momento, é muito delicado: ele está rebatendo uma acusação de chantagem, e o jornal, ao utilizar tal verbo, desacredita sua fala. Logo após os verbos atacar e acusar, o jornal utiliza a expressão "deu o seu diagnóstico", equivalente ao verbo diagnosticar, classificado por Gavazzi e Rodrigues na categoria "valorização positiva", que é aquela em que a figura do entrevistado é enaltecida, colocando-o em posição de superioridade. Na verdade, não é esse o caso, mas o mínimo que se espera de uma pessoa que está fazendo acusações tão sérias é uma explicação para os fatos denunciados. Por essa razão, acreditamos que a função do termo é a mesma dos "verbos indicadores de força do argumento" e sua ação é a "polemização". O verbo definir, empregado 2 vezes no texto, organizador "de um momento argumentativo no conjunto do discurso", é classificado por Gavazzi e Rodrigues como um verbo apenas "descritivo", porém sua ação deixa de ser "neutra" no texto quando ele vem acompanhado da expressão modal "com frieza calculada", e passa a valorizar negativamente a fala do entrevistado. $O$ verbo revelar, indicador de "afirmações positivas", mostra que o fato revelado era um segredo que agora era tirado de sua condição velada e, desse modo, cria "polemização". Advertir, classificado como um dos "verbos interpretativos do caráter ilocutivo do discurso referido", age de maneira a criar "polemização", no momento em que o entrevistado diz não temer por sua segurança, pois há muitas pessoas do governo envolvidas em suas denúncias. Assim, o entrevistado "apimenta" ainda mais a discussão e gera expectativa quanto ao seu depoimento na Comissão de Ética da Câmara:

(3) "Na entrevista, Jefferson contou que, logo após a divulgação da primeira denúncia dos Correios, os ministros José Dirceu e Aldo Rebelo tentaram convencêlo a atrair a crise para si - e depois ele seria ajudado a livrar-se do problema. (...) 
O parlamentar fluminense atacou seletivamente o comando do PT, nomeando as pessoas que busca atingir: "Genoino, Delúbio, Silvinho Pereira (secretário-geral do partido), Zé Dirceu. É esta a cabeça', acusou. E deu o seu diagnóstico: 'O PT entendia, na sua cabeça, na sua cúpula, que era muito mais barato alugar um deputado do que discutir com os partidos um projeto de governo'.

Nessa parte da entrevista, ele acusou diretamente o ministro José Dirceu. Disse que vários ministros (mencionou Ciro Gomes, Paulo Bernardo, Aldo Rebelo e José Dirceu) quiseram ir a sua casa para demovê-lo a resistir à primeira denúncia e retirasse sua assinatura da CPI. Jefferson teria se recusado a recebê-los. 'No dia seguinte', contou, 'eu estava tomando banho, toca o interfone, a empregada aqui de casa, a Elza, manda subir os ministros Aldo Rebelo e Zé Dirceu. (...)

Com o passar dos dias, percebeu um erro tático e disse ao ministro Walfrido dos Mares Guia: 'Vão botar tudo no colo do PTB'. E acrescentou: "Eu vejo nitidamente o dedo desse segmento - Zé Dirceu, Genoino, Delúbio - para colocar esse cadáver podre no colo do PTB', reiterou agora.

$\mathrm{Na}$ entrevista, Jefferson rebateu a afirmação de Delúbio - de que estaria fazendo chantagem com o PT e o governo. 'No ano passado, eu falei do mensalão aos ministros. Isso não é chantagem. Chantagear é para ganhar dinheiro', esquivou-se.

E definiu, com frieza calculada o estado das relações do PTB com o governo: 'Chegamos a um ponto em que se exauriu a relação. Há companheiros no partido que pensam que podem continuar na base do governo. Eu entendo que acabou a relação'.

Antes, revelou as penosas conversas sobre a repartição de cargos, quase todas, segundo ele, feitas numa sala ocupada por Sílvio Pereira, secretário-geral do PT, em pleno Palácio do Planalto.

Com a mesma frieza, passou mais um recado para garantir a tensão dos próximos dias: reconheceu que 'as coisas têm de ser paulatinas' e explicou por que tem falado em conta-gotas para contar o que sabe. 'Se eu falo paulatinamente, não é por chantagem. É para ir mostrando como as coisas se deram.', explicou, como se estivesse compondo um roteiro de novela.

No arremate, o recado final: ele não se sente ameaçado em sua segurança pessoal. 'Se fizerem alguma coisa comigo', advertiu, 'cai a República'. (Jornal O Estado de S.Paulo)

O jornal $O$ Estado de S.Paulo, concluindo esta análise, faz uma utilização dos verbos de elocução muito diversa da Folha. Os "verbos indicadores de posições oficiais e afirmações positivas", embora apareçam também em $O$ Estado, não só criam um efeito de "imparcialidade", mas também agem polemizando e valorizando negativamente a figura do entrevistado. Os outros verbos, em sua maioria, têm a função de organizar a argumentação, agindo sempre no sentido de polemizar ou valorizar negativamente o entrevistado. $O$ Estado, portanto, posiciona-se claramente contra o entrevistado, revelando suas convicções políticas, ideológicas e, por que não dizer, econômicas. Afinal o "furo" de reportagem, empregando aqui um jargão jornalístico, não foi seu, mas de seu concorrente. A Folha, porém, ao se colocar em posição "neutra", não revela menos do que $O$ Estado suas convicções políticas ou ideológicas, apenas mostra seu grau de comprometimento com uma fonte de informação que, dependendo do tratamento que lhe for dado, pode "secar". 


\section{O uso das aspas}

É muito comum, na comunicação entre as pessoas, a citação do discurso alheio, quer seja em uma conversa informal ou discursos proferidos por autoridades, quer seja na literatura, nas cartas, na imprensa. No último caso, o discurso alheio representa grande parte do material publicado. Maingueneau (2004:138) denomina "discurso citante" o enunciado jornalístico, a "voz do jornalista", e "discurso citado" a "voz do outro", aquele a quem o texto jornalístico se refere. Quando se trata da citação do discurso alheio, não se trata de reprodução desse discurso, mas de uma enunciação sobre outra enunciação (idem:139).

Segundo Authier-Revuz (2001), além das tradicionais formas de citação do discurso - DD, DI e DI livre -, há outras formas de se relatar um discurso dentro de outro discurso. ${ }^{10}$ Dentre elas, selecionamos o estudo de uma das formas marcadas, unívocas, de representação do DR, no caso o DD, e uma das formas marcadas que exigem um trabalho interpretativo, no caso a "ilha textual em DI". Salientamos que, nos dois casos, privilegiamos o uso das aspas, as quais indicam a menção ao enunciado (cf. Maingueneau, 2004: 157).

A respeito do DD, sabe-se que literalidade, objetividade e fidelidade não são suas características; ele deve ser visto como a teatralização de uma enunciação. O DD pode relatar uma enunciação sonhada ou futura, por exemplo, e, mesmo nos casos em que essa enunciação tenha sido efetivamente proferida, "trata-se apenas de uma encenação visando criar um efeito de autenticidade" (Maingueneau, 2004: 141).

Abandonada, portanto, a idéia de literalidade e objetividade do DD, percebemos que sua escolha, em qualquer situação de comunicação, aponta para alguns objetivos essencialmente argumentativos, dentre eles:

a) a intenção de criar autenticidade;

b) a intenção de distanciar-se daquilo que foi dito, ou porque o enunciador não quer assumir para si essa responsabilidade ou por respeito à autoridade de quem disse;

c) e, por último, para mostrar-se objetivo. (cf. Maingueneau, 2004:142)

\footnotetext{
${ }^{10}$ Segundo a autora, ampliando o leque de opções da gramática tradicional, várias são as formas de se relatar um discurso dentro de outro discurso:

a) modos explícitos de representação, que se compõem de formas marcadas, unívocas, e de formas marcadas que exigem um trabalho interpretativo; o primeiro caso compreende o DD, o DI e a modalização em discurso segundo sobre o conteúdo e sobre as palavras. No caso das formas que exigem um trabalho interpretativo como referência a outro discurso, encontramos o conjunto das aspas, itálico, entonação e modalização autonímica.

b) formas puramente interpretativas, que compreendem o discurso direto livre, o DIL, as citações escondidas, alusões, reminiscências.
} 
A questão do uso do DD como estratégia discursiva (Leite, 2005: 85) fica ainda mais clara quando o enunciador do discurso citado o emprega para referir-se a falas suas ou de outras pessoas, com o objetivo, dentre outras coisas, de convencer o seu interlocutor daquilo que ele diz (cf. Leite, 2005: 90). É muito comum, nas entrevistas, que o entrevistado relate enunciações passadas suas e de outras pessoas, seus interlocutores de então. Ao fazer isso, porém, o faz carregado de subjetividade, pois age como um "filtro" dessas enunciações, "fazendo prevalecer as suas próprias interpretações dos acontecimentos e dos discursos passados" (Carreira, 2001: 161). Tal procedimento é bastante freqüente em nosso corpus, principalmente no que se refere ao uso do DD.

O que devemos, sempre, ter em mente é que, mesmo que a citação seja textual, o que se está reproduzindo é uma enunciação inserida numa nova enunciação, ou seja, num dado discurso que contém a mensagem $\mathbf{M}$, entre dois pares de interlocutores $\mathbf{L}$ e $\mathbf{R}$, ocorrido numa determinada situação SIT, com seu tempo $\mathbf{T}$, seu lugar $\mathbf{L}$ e outros dados referenciais, ocorre uma referência a um outro discurso que contém a mensagem $\mathbf{m}$, entre dois pares de interlocutores $\mathbf{l}$ e $\mathbf{r}$, ocorrido numa determinada situação sit, com seu tempo t, seu lugar I e outros dados referenciais. (cf. Authier-Revuz, 2001:146)

Para delimitar a fronteira entre o discurso citante e o discurso citado, utiliza-se, dentre outras marcas, as aspas. O sentido a ser dado aos elementos entre aspas pode variar significativamente, uma vez que, como já dissemos, o que um enunciador cria, ao citar um outro discurso, é uma nova enunciação. Interpretar as aspas passa a ser uma atividade fundamental a ser desenvolvida pelo co-enunciador quando da leitura de um texto, "um sinal a ser interpretado" (Maingueneau, 2004: 160)

Selecionamos, abaixo, os trechos dos jornais Folha de S.Paulo e O Estado de S.Paulo, no período de 6 a 12 de junho de 2005, nos quais verificamos o uso das aspas no DD, com ou sem verbo de elocução, e na "ilha textual em DI". Denominamos E o discurso citante e e o discurso citado, o qual estará em negrito.

\subsection{As aspas e o DD sem verbo de elocução}

Os trechos abaixo confirmam a tendência verificada em nosso estudo, no uso do DD sem verbo de elocução, da utilização de e para confirmar o que é dito em E. Emprega-se, portanto, o DD para comprovar as afirmações que vão sendo feitas ao longo do texto, confirmando o postulado de Maingueneau (2004) de que o DD seria uma encenação visando criar um efeito de autenticidade. Notemos que, em a e b, temos em $\mathbf{E}$ uma interpretação das situações descritas por meio das expressões "se declarou abandonado" e "poupa". Em nenhum momento o interlocutor I disse "estou me declarando abandonado" ou "eu poupo o presidente". Essas são interpretações de $\mathbf{L}$ para as situações descritas e direcionam a interpretação dos enunciados, como afirma Marcuschi, para quem a informação de opinião "é sempre a apresentação de um discurso interpretado" ( Marcuschi, 1991: 78). Confirma-se, também, a afirmação de Maingueneau (2004: 141), que chama a atenção para o fato de que o enunciador de $\mathbf{E}$ possui muitos meios para dar um enfoque pessoal a e. Acreditamos que os exemplos a e b revelem um desses meios: 
a) Sobre o Palácio do Planalto, se declarou abandonado após as recentes denúncias de corrupção envolvendo seu nome. "O governo se afastou, correu. Não são parceiros, não são solidários."

b) Na entrevista, Jefferson poupa Luiz Inácio Lula da Silva. "Deixaram o presidente completamente desinformado."

c) Levado ao centro do noticiário pelos escândalos nos Correios e no IRB e transformado em pivô da pior crise política enfrentada por Lula a partir da denúncia do "mensalão", Jefferson nega ter gravações comprometedoras contra autoridades do governo, contrariando os rumores que tomaram conta de Brasília ao longo da semana. "Tenho a palavra e a vivência desta relação de dois anos e meio com o governo do PT."

d) A partir daí, volta a dizer Jefferson, a mesada teria cessado. "O corpo mole [na Câmara] é porque está faltando aquilo que o Delúbio sempre transferiu a líderes e presidentes da base."

e) Do apartamento funcional que ocupa em Brasília, Roberto Jefferson concedeu por telefone a entrevista que segue abaixo e nas duas páginas seguintes. O deputado diz não temer por sua segurança. "Se fizerem alguma coisa comigo, cai a República."

O exemplo f é essencialmente polifônico. Nele, alternam-se dois planos de enunciação: o plano do interlocutor $\mathbf{L}$, no caso o jornalista, e o plano do interlocutor $\mathbf{l}$, no caso o deputado Roberto Jefferson, em conversa com o interlocutor $\mathbf{r}$, o presidente Lula. As únicas marcas tipográficas que delimitam tais planos são as aspas:

f) Jefferson conta que, em janeiro deste ano, falou com Lula. "Presidente, o Delúbio vai botar uma dinamite na sua cadeira. Ele continua dando 'mensalão' aos deputados." “Que 'mensalão'?”. Jefferson explicou. "O presidente Lula chorou." $E$ depois da conversa com Lula? "Tenho notícia de que a fonte secou. A insatisfação está brutal [na base aliada] porque a mesada acabou.” (ANEXO B2)

O interlocutor $\mathbf{L}$, ao empregar tal recurso, assume algumas informações e não assume outras. Por exemplo: L assume a informação "Jefferson explicou", embora não tenha provas de que isso tenha realmente ocorrido, uma vez que, na entrevista, o deputado apenas diz: "Aí eu expliquei ao presidente". Logo em seguida, coloca entre aspas a informação: "O presidente Lula chorou", não a assumindo. Se a assumisse, poderia ter dito: "Jefferson explicou e o presidente Lula chorou", mas assumi-la seria acreditar nela e se posicionar claramente, o que, como vimos na análise dos verbos de elocução, a Folha evitou fazer. A ausência de introdutor explícito confere dinamismo ao relato, como se fossem várias cenas de uma peça de teatro, e transfere ao co-enunciador a tarefa de atribuir o discurso citado às fontes corretas. 


\subsection{As aspas e o DD com verbo de elocução}

Os próximos exemplos sob análise possuem verbos de elocução e, por essa razão, exercem um papel diferente dos anteriores; neles, o DD vai acrescentando informações inéditas, e os verbos, por sua vez, vão condicionando sua interpretação.

Os exemplos $\mathbf{g}$ e $\mathbf{h}$ trazem a admissão de culpa de $\mathbf{l}$ e a revelação de sua fragilidade, confirmada no uso do verbo "confessou", introduzindo o DD e, portanto, já condicionando a sua interpretação. Nesse caso, o DD cria a autenticidade necessária para relatos tão subjetivos:

g) 'Sim, eu preciso da CPI, eu errei’, diz Jefferson

h) E confessou: "[O momento] é difícil, mas eu vou enfrentar, vou enfrentar de peito aberto".

No relato pertencente a e, abaixo, l, ao narrar uma sucessão de fatos em ordem cronológica ("No dia seguinte"), pretende dar veracidade ao seu discurso e, como afirma Preti (2004: 21), "pode ser analisado como um recurso de que o falante dispõe para referirse a eventos ocorridos e que têm ligação com o tema sobre o qual está falando". L, porém, ao empregá-lo em $\mathbf{E}$ com o verbo "contou", além de não se responsabilizar por e, direciona o leitor a interpretá-lo como uma história, como já vimos na análise dos verbos de elocução. Atentemos para o emprego do futuro do pretérito no verbo "teria", indicando um fato hipotético:

i) O parlamentar fluminense atacou seletivamente o comando do PT, nomeando as pessoas que busca atingir: "Genoino, Delúbio, Silvinho Pereira (secretário-geral do partido), Zé Dirceu. É esta a cabeça”, acusou. E deu o seu diagnóstico: “O PT entendia, na sua cabeça, na sua cúpula, que era muito mais barato alugar um deputado do que discutir com os partidos um projeto de governo".

Nessa parte da entrevista, ele acusou diretamente o ministro José Dirceu. Disse que vários ministros (mencionou Ciro Gomes, Paulo Bernardo, Aldo Rebelo e José Dirceu) quiseram ir a sua casa para demovê-lo a resistir à primeira denúncia e retirasse sua assinatura da CPI. Jefferson teria se recusado a recebê-los. "No dia seguinte", contou, "eu estava tomando banho, toca o interfone, a empregada aqui de casa, a Elza, manda subir os ministros Aldo Rebelo e Zé Dirceu. Quando eu saio do banho, estão os dois sentados na sala". 


\subsection{As aspas e a "ilha textual em DI"}

Os exemplos de $\mathbf{j}$ a $\mathbf{p}$ são casos de "ilha textual em DI", em que fragmentos de e são acrescentados ao fio do discurso de $\mathbf{E}$, conservados da sua mensagem de origem, como elementos "intraduzíveis".

Nos casos $\mathbf{j}$ a $\mathbf{n}$, os fragmentos conservados poderiam ser classificados como intraduzíveis por conterem expressões populares ou com forte carga emotiva. É o que Authier-Revuz denominaria a "não-coincidência do discurso consigo mesmo" (2001: 23), uma vez que a linguagem jornalística busca objetividade. Por outro lado, a Folha, em seu Manual de Redação (2006: 66), orienta os jornalistas, no caso de publicação de entrevistas, a não trocar palavras nem modificar o estilo da linguagem da pessoa entrevistada, a qual, no nosso caso, sabe manejar muito bem a linguagem e tem um estilo teatral de se comunicar, com gestos largos e modulações na voz. Ao ser descrito pela jornalista Catia Seabra (Folha de S. Paulo, 6/6/2005, A4), por exemplo, lhe é atribuído o adjetivo "performático". É interessante notar, no exemplo $\mathbf{m}$, que $\mathbf{E}$ se aproveita da rede metafórica criada por e, acrescentando a expressão "limpando a área", que também se refere ao jargão futebolístico:

j) O PT, no entender do deputado, "nos usa [aos partidos aliados] como uma amante e tem vergonha de aparecer conosco à luz do dia".

k) Presidente do PTB diz que o PT trata seu partido "como se fosse gente de segunda" e que vai enfrentar a situação de peito aberto

1)(...) Para ele, o partido do presidente "não tem coração".

m) A sugestão era que Jefferson "matasse no peito" e "puxasse" a crise para o PTB, limpando a área do PT e do governo. (...)

n) Segundo Jefferson, Dirceu teria repetido o pedido que antes fora feito por Chinaglia - "matar no peito e puxar a crise para si", prometendo nomear um indicado seu para a Eletronorte. Ele, então, concordou em começar a "matar no peito", isto é, retirar a assinatura da CPI.

No exemplo o, levantamos a hipótese de que existe uma certa ironia ao se salientar apenas o termo "fundamental", pois seu uso chama a atenção para o seguinte fato: Roberto Jefferson mudou de idéia ao assinar a citada lista, retirar seu nome dela e, novamente, decidir-se por assiná-la. Assinalar localmente tal termo não pode ser visto como um mero acaso:

o)Depois de assinar e dias depois retirar seu nome da lista de parlamentares a favor da CPI dos Correios no Congresso, Roberto Jefferson disse ontem que a instalação da comissão é "fundamental" para a sua imagem e de seu partido. 
O exemplo p mostra como se pode construir um texto com fragmentos de discurso citado, construindo novos sentidos. É o que o interlocutor $\mathbf{L}$ faz em boa parte de $\mathbf{E}$, na qual se propõe a analisar trechos da primeira entrevista de Roberto Jefferson (6/6/2005), os quais, segundo $\mathbf{L}$, são escandalosas revelações de como é feita a política no Brasil e aos quais não se deu tanta atenção. Ou seja, $\mathbf{L}$, na introdução de seu texto, já diz a que veio: esmiuçar trechos da entrevista que merecem maior atenção, pois são reveladores de graves procedimentos. Para fazer isso, emprega e, que, nesse contexto, adquire valor completamente diverso do original. No original, era recurso argumentativo favorável a Roberto Jefferson, que não via gravidade em procedimentos correntes na política nacional e os empregava para explicar suas atitudes; recortado, porém, do original, e empregado no texto de $\mathbf{E}$, transforma-se em recurso argumentativo desfavorável não só a Roberto Jefferson, mas a toda a classe política brasileira: são suas palavras usadas contra ele:

p) Sobre a reportagem da revista Época desta semana, na qual se aponta um sorveteiro como "laranja" do deputado em duas rádios, Jefferson declarou que um empresário “...pediu duas concessões de rádio, e eu ofereci”.

Aqui podemos perceber claramente o valor das aspas, que chamam a atenção para $\mathbf{e}$ e comprovamos que "o 'mesmo' enunciado em dois lugares distintos corresponde a dois discursos distintos." (Maingueneau, 2004:54)

\section{Conclusão}

As análises permitiram explicitar estratégias lingüístico-discursivas empregadas pelos jornalistas na transmissão da notícia.

A primeira delas, a passagem do oral para o escrito, interferiu de maneira decisiva na força ilocutória dos atos de linguagem do entrevistado, o qual, em posição de acusado, empregou os recursos lingüístico-discursivos analisados como estratégias argumentativas para colocar a opinião pública a seu favor e o tratamento dado pelo jornal ao seu discurso acabou por esvaziá-lo desse seu objetivo, fazendo prevalecer o discurso da imprensa e comprovando que a retextualização pode ser um eficaz instrumento de manipulação da notícia, porque opera por meio de recursos que os leitores, e também os entrevistados, não dominam, e que atuam muito mais no nível discursivo do que no lingüístico.

Quanto ao uso dos verbos de elocução, a análise comparativa entre os jornais Folha de S.Paulo e $O$ Estado de S.Paulo mostrou-se bastante satisfatória, uma vez que, como prevíamos, assinalamos diferenças quanto à ação dos verbos de elocução. Na Folha, preferiu-se o uso de verbos como afirmar e dizer, que agiram criando um "efeito de imparcialidade", apropriado para o jornal detentor da fonte exclusiva, evitando polemizar ou valorizar positiva ou negativamente a figura do entrevistado. Já, em $O$ Estado, houve o predomínio de verbos como acusar e insistir, que agiram, respectivamente, polemizando ou 
valorizando negativamente a figura do entrevistado. Em resumo, quanto ao uso dos verbos de elocução, confirmamos que ele pode orientar a interpretação do DD, configurando-se em um eficaz recurso de manipulação de idéias.

Para a análise do DR, empreendemos uma divisão que levou em consideração o uso do DD com a presença ou não de verbo introdutor explícito, pois, se, como confirmamos com o estudo dos verbos de elocução, sua presença interfere na interpretação do DR, sua ausência poderia pressupor uma interferência menor nessa interpretação. O que observamos nos casos de ausência de verbo de elocução foi uma tendência no uso do DD como recurso argumentativo, aparecendo sempre depois do DR em DI, com a intenção de criar um "efeito de autenticidade" (Maingueneau, 2004) ou, ainda, uma teatralização dos fatos (Maingueneau, 1993). Confirmamos, ainda, um dos postulados de Maingueneau (2004), para quem, ao se relatar um discurso em outro, cria-se um discurso distinto. Desse modo, mesmo sem os verbos de elocução interferindo na interpretação do DD, encontramos o próprio DD conduzindo a interpretação do texto como um todo.

Nos casos de DD com verbo de elocução, confirmamos a forte presença de tais verbos, condicionando a interpretação do DD, que é empregado com os objetivos de criar a autenticidade necessária ao discurso do entrevistado e para promover um distanciamento do enunciador do discurso citante.

Os casos de "ilha textual em DI" revelaram-se, como os dois anteriores casos de uso das aspas, revestidos de intenções do enunciador do discurso citante, confirmando a necessidade de interpretação das aspas "como referência a um outro discurso" (AuthierRevuz, 2001: 143). Assim, conservaram-se fragmentos do discurso citado que continham expressões populares, por exemplo, que Authier-Revuz denominaria a "não-coincidência do discurso consigo mesmo" (2001: 23); por outro lado, recorrentes foram os empregos do recurso da "ilha textual em DI" com claros objetivos persuasivos.

Concluindo, nosso trabalho vem demonstrar, mais uma vez, que a enunciação é um ato único, impossível de ser reproduzido. Relatar algo que foi dito por alguém, quer na modalidade oral, quer na modalidade escrita, está longe de ser um processo simples e inofensivo. A eliminação de informações aparentemente repetitivas, a escolha da forma de se relatar um discurso - DD, DI, "ilha textual em DI" etc. - são operações muito comuns em nosso dia-a-dia, mas que trazem consigo, em todas as suas instâncias, uma carga muito forte de subjetividade - inerente à linguagem, lembremos.

Sobre diferenças no trato da notícia nos diferentes jornais analisados, concluímos que o comprometimento com a fonte de informação obriga o jornalista a buscar efeitos de "imparcialidade" ao escolher as estratégias lingüístico-discursivas que usará, quer seja na escolha dos verbos de elocução, quer seja na escolha dos trechos em DD, mas tais estratégias são apenas uma encenação, pois, como vimos, a Folha foi muito eficaz na neutralização dos efeitos pretendidos pelo entrevistado ao fazer a retextualização. 


\section{Referências bibliográficas}

ANDRADE, Maria Lúcia da Cunha V. de Oliveira (2000). A digressão como estratégia discursiva na produção de textos orais e escritos. In: PRETI, Dino (org.). Fala e escrita em questão. São Paulo: Humanitas/FFLCH/USP, p. 99-128 (Projetos Paralelos - NURC/SP, 4).

AUTHIER-REVUZ, Jacqueline (2001). Palavras incertas: as não-coincidências do dizer. Campinas, SP: Editora da UNICAMP.

BAKHTIN, Mikhail (1981). Marxismo e Filosofia da Linguagem: Problemas fundamentais do Método Sociológico na Ciência da Linguagem. Trad. Michel Lahud e Yara Frateschi Vieira. 2. ed. São Paulo: Hucitec.

BARROS, Diana Luz Pessoa de (1998). Procedimentos e recursos discursivos da conversação. In: PRETI, Dino (org.). Estudos de língua falada: variações e confrontos. São Paulo: Humanitas/FFLCH/USP, p.47-69 (Projetos Paralelos - NURC/SP, 3).

BENVENISTE, Émile (1989). Problemas de lingüística geral II. Campinas, SP: Pontes.

CARREIRA, Maria Helena de Araújo (2001). Semântica e Discurso: Estudos de Lingüística Portuguesa e Comparativa (Português/Francês). Portugal: Porto Editora (Coleção Lingüística Porto Editora).

GARCIA, Othon Moacir (1988). Comunicação em prosa moderna: Aprenda a escrever, aprendendo a pensar. 14.ed. Rio de Janeiro: Editora da Fundação Getúlio Vargas.

GAVAZZI, Sigrid e RODRIGUES, Tânia Maria (2003). Verbos dicendi na mídia impressa: categorização e papel social. In: PAULIUKONIS, Maria Aparecida Lino e GAVAZZI, Sigrid (Orgs.). Texto e Discurso: mídia, literatura e ensino. Rio de Janeiro: Lucerna, p. 5161.

HILGERT, José Gaston (2001). Procedimentos de reformulação: a paráfrase. In: PRETI, Dino (org.). Análise de textos orais. 5. ed. São Paulo: Humanitas/FFLCH/USP, p. 103-127 (Projetos Paralelos - NURC/SP, 1).

LEITE, Marli Quadros (2005). O diálogo no diálogo: a dupla expressão do discurso do outro. In: PRETI, Dino (org.). Diálogos na fala $e$ na escrita. São Paulo: Humanitas/FFLCH/USP, p. 85-117 (Projetos Paralelos - NURC/SP, 7).

MAINGUENEAU, Dominique (1993). Novas tendências em análise do discurso. Trad. Freda Indursky. 2. ed. Campinas: Cortez/Editora da Universidade Estadual de Campinas. (2004). Análise de textos de comunicação. Trad. Cecília P. de Souza-e-Silva, Décio

Rocha. 3. ed. São Paulo: Cortez. 
MARCUSCHI, Luiz Antônio (1991). A ação dos verbos introdutores de opinião. In: INTERCOM - Revista Brasileira de Comunicação. São Paulo, Ano XIV, $\mathrm{n}^{\circ}$ 64, jan/jun (7492).

(2003). Da fala para a escrita: atividades de retextualização. 4. ed. São Paulo: Cortez.

PRADO, Valéria Aparecida Galioti Silva (2006). O percurso de uma entrevista no jornal: alguns procedimentos lingüístico-discursivos na passagem do oral para o escrito e suas consequiências para a interpretação da enunciação. São Paulo.159f. Dissertação (Mestrado em Língua Portuguesa) - Pontifícia Universidade Católica de São Paulo - PUCSP.

PRETI, Dino (org.) (2001). Análise de textos orais. 3.ed. São Paulo: Humanitas/FFLCH/USP (Projetos Paralelos - NURC/SP, 1). (2004). Estudos de língua oral e escrita. Rio de Janeiro: Lucerna.

URBANO, Hudinilson (2003). Reflexões em torno de "falar" e "dizer" na fala e na escrita. In: PRETI, Dino (org.). Léxico na língua oral e na escrita. São Paulo: Humanitas/FFLCH/USP, p. 139-168 (Projetos Paralelos - NURC/SP, 6).

FOLHA DE S.PAULO (2006). Manual da Redação. 10.ed. São Paulo: Publifolha.

\begin{abstract}
The passage from oral mode to the written one, a common procedure in human communication, causes discourse distortion. This has been analysed in this research. This work aims at recognising some linguistic discursive strategies used by journalists while conveying the news to the readers by analysing the course of an interview, from the interviewee's oral report to the interview publication in the newspaper. The purpose of this study is to what degree such strategies can be used as an instrument of ideas manipulation, besides searching for differences in dealing with news in both analysed newspapers, tabing into account the involvement of one of them with the information.
\end{abstract}

Keywords: Discourse Analysis. Enunciation Theory. Polyphony. Related Discourse. Direct Speech. Inverted Commas. Elocution Verbs. 